\title{
Percutaneous sclerotherapy of a giant mediastinal lymphangioma
}

\author{
A. Desir*, B. Ghaye*, B. Duysinx* and R.F. Dondelinger*
}

\begin{abstract}
The present study reports a case of percutaneous sclerotherapy of a giant mediastinal cystic lymphangioma using Ethibloc ${ }_{\mathbb{B}}$ (Ethicon, Norderstedt, Germany) and absolute ethanol in a 59-yr-old female.
\end{abstract}

The tumour, situated predominantly in a retrocardiac location, caused dyspnoea and dysphagia by compression and was considered unresectable. Follow-up computed tomography 3 yrs after treatment showed a $90 \%$ volume reduction of the tumour. The patient is currently asymptomatic.

To the best of the present authors' knowledge, percutaneous transthoracic sclerotherapy of a mediastinal lymphangioma has not previously been reported in the literature available in English.

KEYWORDS: Interventional, lymphangioma, lymphangiomatosis, mediastinum, radiology, sclerotherapy

ymphangiomas are rare, benign, congenital malformations of the lymphatic system, consisting of well-differentiated lymphatic vessels and spaces, interconnected in a multicystic or sponge-like pattern [1]. Lymphangiomas typically occur in young children, 95\% involve the neck or axilla, and $\sim 10 \%$ extend into the anterior mediastinum. Only $\sim 1 \%$ of all lymphangiomas are confined to the chest, representing $0.7-4.5 \%$ of all mediastinal masses; these are usually seen in adults [1, 2]. Thoracic lymphangiomas may remain asymptomatic for years and become apparent with manifestations related to compression of intrathoracic structures, including respiratory symptoms or dysphagia.

Treatment of mediastinal lymphangioma remains difficult. Surgery is the method of choice but complete resection can prove technically problematic because of the insinuating nature of the tumour. Recurrence rates range $0-27 \%$ and 50 $100 \%$, following complete or incomplete excision, respectively [3]. Other therapeutic options include radiation therapy and iterative aspiration under imaging guidance [4]. In the current literature, sclerotherapy has emerged as an efficient treatment modality for head and neck lymphangiomas [4]. The present study reports a case of percutaneous sclerotherapy of a macrocystic giant mediastinal lymphangioma in an adult.

\section{CASE REPORT}

In 1996, a 59-yr-old female presented with cough, dyspnoea and frequent episodes of haemoptysis.
Computed tomography (CT) demonstrated a macrocystic mediastinal mass in the right paratracheal area and splenomegaly. The mediastinal tumour extended from the level of the aortic arch down to the carina. The largest diameter was $5 \mathrm{~cm}$. Splenectomy and mediastinoscopy yielded a histopathological diagnosis of splenic and mediastinal lymphangiomatosis. Fibroscopy showed bronchial mucosal vesicles, considered to be responsible for the haemoptysis. Surgery was not considered a therapeutic option in two centres. In an attempt to provide relief, several palliative interventions were performed over the following 6 yrs, including endobronchial laser therapy and thoracic radiation therapy (18.5 Gy), resulting in temporarily improved symptoms.

In 2003, the patient presented to the University Hospital of Liège (Liège, Belgium) with dysphagia, recurring and increasing cough, and grade IIB dyspnoea. CT and magnetic resonance imaging showed a significant increase in tumour size, with the lymphangioma extending caudally to the retrocardiac space. The largest diameter was $18 \mathrm{~cm}$. Compression of the distal oesophagus, carina and particularly the left atrium was demonstrated (figs 1 and 2a). The patient was referred for percutaneous sclerotherapy under CT guidance. The lymphangioma was punctured with an F5 Teflon-sheathed needle via a right paravertebral route. Aspiration of $750 \mathrm{~mL}$ of brownish fluid (a mixture of lymph and old blood) resulted in the collapse of the main retrocardiac

\section{AFFILIATIONS}

*Depts of Medical Imaging, and \# Medicine, University Hospital of Liège, Liège, Belgium.

\section{CORRESPONDENCE}

B. Ghaye

Dept of Medical Imaging

University Hospital of Liège

B 35

B-4000 Liège

Belgium

Fax: 3243667772

E-mail: bghaye@chu.ulg.ac.be

Received:

February 062007

Accepted after revision:

January 292008

STATEMENT OF INTEREST

None declared. 


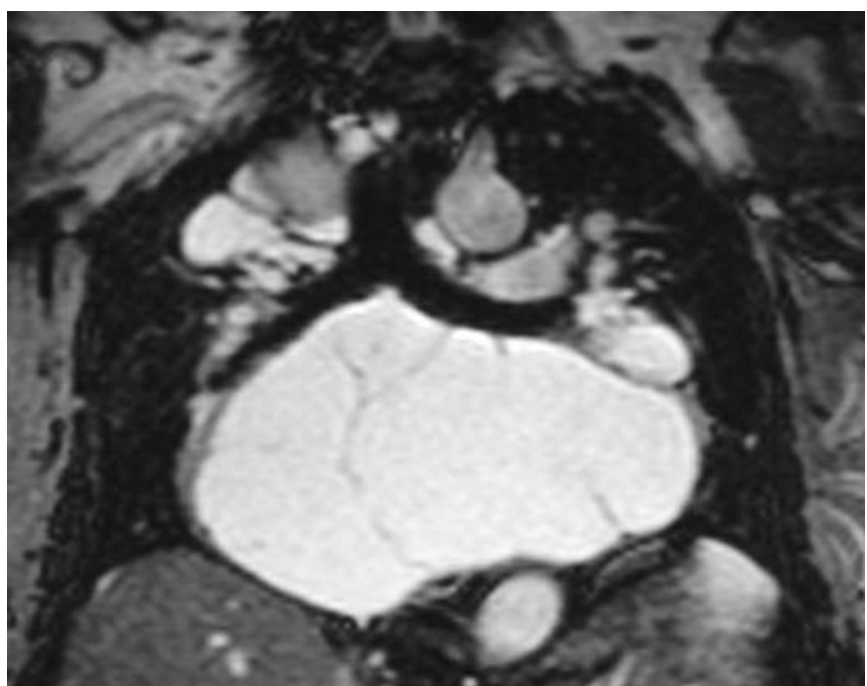

FIGURE 1. T2-weighted coronal magnetic resonance imaging scan taken before treatment showed a large multicystic mediastinal lymphangioma predominantly involving the subcarinal space and compressing mediastinal structures, i.e. right and left main bronchi, which are displaced cranially.

component, while other mediastinal and right parahilar cysts persisted. Under CT monitoring, a mixture of $42 \mathrm{~mL}$ of Ethibloc ${ }$ (Ethicon, Norderstedt, Germany) and $12 \mathrm{~mL}$ of absolute ethanol was injected through the Teflon sheath without re-aspiration, until the collapsed cavity was homogeneously filled. Fever, chest pain and dyspnoea occurred on the next day and were treated with broad-spectrum antibiotics for 10 days. At 1-month follow-up the patient still complained of the initial symptoms. Follow-up CT demonstrated only a moderate reduction in size of the lymphangioma $(20 \%)$. The patient was readmitted for two consecutive injections of $7 \mathrm{~mL}$ of Ethibloc $\mathbb{}$ mixed with $4 \mathrm{~mL}$ of ethanol, administered via a posterior percutaneous approach. Clinical symptoms resolved within
1 month without recurrence. Follow-up chest CTs were obtained every 3 months for 2 yrs, and once at 3 yrs. The lesion progressively regressed to $10 \%$ of its initial volume, with thickening of the cyst wall (fig. 2).

\section{DISCUSSION}

The present study reports the successful percutaneous sclerotherapy of a giant macrocystic mediastinal lymphangioma. Treatment was indicated because of tumour growth $(>300 \%$ increase in volume in 6 yrs) and compression of adjacent structures causing invalidating symptoms. Surgery and radiation therapy were impossible because of the size and multiloculation of the lesion. Abstention was not considered an option in this symptomatic patient, despite the fact that spontaneous regression of lymphangioma has been reported, ranging 1.6$15 \%$, depending on tumour characteristics. This is most frequently seen in small head and neck locations in infants [3] Percutaneous sclerotherapy, using acetic acid, fibrin sealant, Ethibloc ${ }_{\circledast}$ or OK432 (Picibanil; Chungai Pharmaceuticals Co., Tokyo, Japan) has emerged as an efficient treatment modality for superficial head and neck lymphangiomas [3]. The results of sclerotherapy in general are reported to be good to excellent in $50-80 \%$ of head and neck lymphangiomas $[3,4]$. Total reduction of a large cervical lymphangioma extending into the anterior mediastinum has been reported with acetic acid sclerotherapy using cervical access [5]. When using Ethibloc®, MARTINOT et al. [6] reported that excellent volume reduction was obtained in $80 \%$ of superficial macrocystic cervical lymphangiomas; DuBOIs et al. [3] noted $64 \%$ excellent and $34 \%$ satisfactory results.

As symptoms persisted, the present authors treated the patient using repeated percutaneous sclerotherapy with Ethibloc ${ }^{\circledR}$ enriched with ethanol. Ethibloc ${ }^{\circledR}$ is a radio-opaque, viscous zein emulsion, which precipitates after contact with blood or other ionic agents within $5 \mathrm{~min}$. Ethibloc ${ }^{\circledR}$ is highly efficient as a sclerosing agent and has been used in other indications, e.g. for renal artery embolisation and as a treatment of severe chronic pancreatitis by occlusion of the ductal system [7, 8].
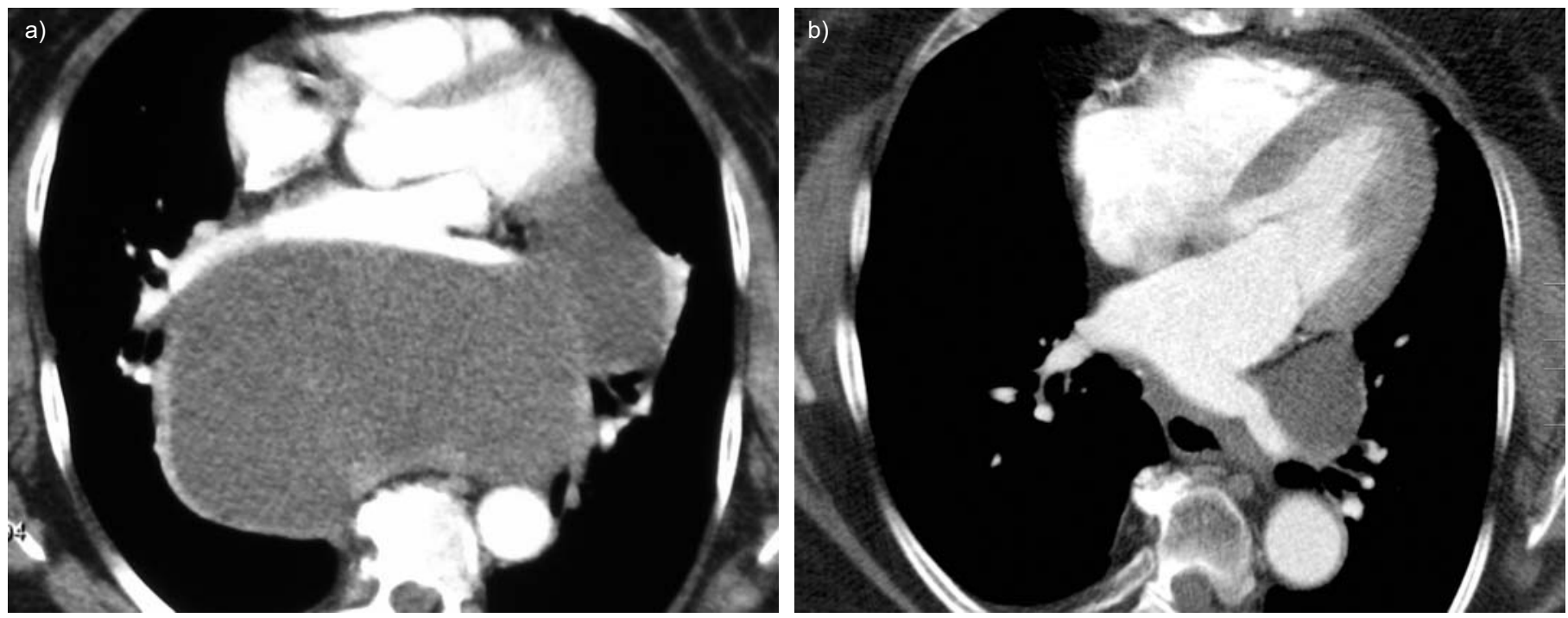

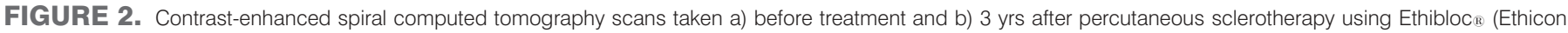
Norderstedt, Germany) and absolute ethanol, showed a $90 \%$ decrease in volume of the mediastinal lymphangioma and marked reduction of compression of the left atrium. 
After injection into a cystic tumour, the precipitated agent induces sclerosis, which may be enhanced by adding ethanol. Ethibloc ${ }^{\circledR}$ biodegrades within 30 days [9].

There is no published evidence regarding the optimal dose of Ethibloc ${ }^{\circledR}$ and ethanol to be injected. In the present case, the required dose of Ethibloc ${ }^{\circledR}$ was adjusted to the volume of the lesion, based on the authors' clinical experience with other lesions treated. The current authors enriched Ethibloc ${ }_{\circledR}$ with absolute ethanol to enhance the sclerosing effect. The dose of ethanol was empirically adjusted compared to Ethibloc ${ }_{\circledR}$, to a ratio of one quarter for the first treatment and of one half for the second session. It was expected that the repetitive treatments reduced the number of secreting cells. Eventually, after three procedures, a tumour volume reduction of $\sim 90 \%$ was obtained. To the best of current authors' knowledge, only one other case of percutaneous transthoracic sclerotherapy of mediastinal lymphangioma, using OK432, has been reported in the Japanese literature [10].

Complications of sclerotherapy are generally minor. In the present case, fever and dyspnoea developed on the day after the first procedure and resolved rapidly. Inflammatory reaction, temporary increase in the volume of the lesion, and secondary infection are reported post-procedure complications. External fistulisation of Ethibloc ${ }^{\circledR}$ several weeks to months later has been reported in superficial lesions. The use of Ethibloc ${ }^{\circledR}$ is only contraindicated in cases of iodine allergy due to its iodine content. Otherwise the agent is well tolerated, due to its biodegradability. Intracystic injection of ethanol may transiently produce ethanolaemia by systemic resorption. Extra-cystic spread of ethanol must be avoided to prevent inadvertent chemical lysis of mediastinal nerve structures.

In conclusion, repeated percutaneous sclerotherapy may be an effective treatment option in giant mediastinal lymphangioma.

\section{REFERENCES}

1 Faul J, Berry G, Colby T, et al. Thoracic lymphangiomas, lymphangiectasis, lymphangiomatosis, and lymphatic dysplasia syndrome. Am J Respir Crit Care Med 2000; 161: 1037-1046.

2 Shaffer K, Rosado-de-Christenson M, Patz E, Young S, Farver C. Thoracic lymphangioma in adults: CT and MR imaging features. AJR Am J Roentgenol 1994; 162: 283-289.

3 Dubois J, Garel L, Abela A, et al. Lymphangiomas in children: percutaneous sclerotherapy with alcoholic solution of zein. Radiology 1997; 204: 651-654.

4 Giguère C, Bauman N, Smith R. New treatment options for lymphangioma in infants and children. Ann Otol Laryngol 2002; 111: 1066-1072.

5 Won JH, Kim BM, Kim CH, Park SW, Kim MD. Percutaneous sclerotherapy of lymphangioma with acetic acid. J Vasc Interv Radiol 2004; 15: 595-600.

6 Martinot V, Descamps S, Février P, et al. Evaluation du traitement des lymphangiomes kystiques par injection percutanée d'Ethibloc ${ }^{\circledR}$ chez 20 patients. [Evaluation of the treatment of cystic lymphangioma by percutaneous injection of Ethibloc ${ }^{\circledR}$ in 20 patients.] Arch Pediatr 1997; 4: 8-14.

7 Kauffmann G, Wimmer B, Rohrbach R, Sommerkamp H, Kropelin T. Renal embolisation, renal cystography and percutaneous nephrostomy. Radiologe 1980; 20: 308-318.

8 Gall F, Gebhardt C, Meister R, Zirngibl H, Schneider M. Severe chronic cephalic pancreatitis: use of partial duodenopancreatectomy with occlusion of the pancreatic duct in 289 patients. World J Surg 1989; 13: 809-817.

9 Novak D. Embolization materials. In: Dondelinger RF, Rossi P, Kurziel JC, Wallace S, eds. Interventional Radiology. New York, Thieme Medical Publishers, 1990; pp. 295-313.

10 Okubo T, Shimada T, Narita Y, et al. A successful case report on intralesional OK-432 therapy for cystic mediastinal lymphangioma. Kyobu Geka 1998; 51: 1017-1021. 